\title{
Exploring Experiences of Accounting Student Teachers with Digitally Mediated Learning: A Phenomenological Perspective
}

\author{
Medson Mapuya $^{1} \&$ Awelani Melvin Rambuda ${ }^{2}$ \\ ${ }^{1}$ School of Education, Department of Human Sciences, Sol Plaatje University, Kimberley, South Africa \\ ${ }^{2}$ Faculty of Humanities, Department of Educational and Professional Studies, Central University of Technology, \\ Free State, Welkom, South Africa \\ Correspondence: Medson Mapuya, School of Education, Department of Human Sciences, Sol Plaatje University, \\ Kimberley, South Africa.
}

Received: October 19, 2021

Accepted: December 14, $2021 \quad$ Online Published: December 15, 2021

doi:10.5430/ijhe.v11n3p90

URL: https://doi.org/10.5430/ijhe.v11n3p90

\begin{abstract}
Conducted against the backdrop of forced online learning imposed by the COVID-19 pandemic, this study sought to explore the learning experiences of accounting student teachers with digitally mediated learning. Anchored in phenomenological research design, focus group interviews were used to generate qualitative data from purposefully selected accounting student teachers while member checking was used for validation. Content analysis of data revealed sufficient concurrence in the phenomenological voices of students that they experienced anxiety, stress, isolation, demotivation and lack of contact with their classmates. In mitigation of these experiences, the study recommends that lecturers need to develop learning material with which students can interact meaningfully, and create and maintain a live, interactive virtual learning environment in which student learning is monitored and evaluated continuously. The students appreciated the flexibility of digitally mediated learning and its provision for real opportunities for learning beyond the physical learning environment. The study found that digitally mediated learning creates a platform for a creative, innovative and non-contact learning environment in the new educational dispensation of the COVID-19 pandemic era. It therefore calls for a radical paradigm shift in the pedagogical assumptions and practices of lecturers towards a student-centred virtual learning environment which thrives on digital technology.
\end{abstract}

Keywords: accounting student teachers, digitally mediated learning, phenomenological experiences, virtual learning environment

\section{Introduction}

The concept of digitally mediated learning has received tremendous research attention over the last decade from both a national and a global perspective (Bir, 2019; DeMara et al., 2019, Dube, 2020, Krishnakumar \& Rana, 2020; Molise \& Dube, 2020; Prynne, 2021; Sintema, 2020). Coupled with the need to prepare for the fourth industrial revolution, this has made the idea of a virtual learning environment and digitally mediated learning very appealing to the current landscape of higher education (DeMara et al, 2019; Macleod et al., 2016). Thus, in response to the virtual learning environment imposed by the COVID-19 pandemic, institutions of higher learning globally migrated from traditional contact sessions to digitally mediated learning (Prynne, 2021; Wells, 2020).

Dube (2020) and Prynne (2021) argue that the COVID-19 pandemic has not only transformed teaching and learning in the higher education landscape across the globe, but it has also necessitated a radical change in the pedagogical practices of lecturers and ways of student learning. Globally, the advent of the COVID-19 pandemic in 2019 forced lecturers and institutions of higher learning to be innovative and find ways to keep the education agenda alive while observing the non-pharmaceutical measures provided by the World Health Organization (Prynne, 2021). To this effect, Coughlan (2021) and Sintema (2020) argue that digitally mediated learning emerged as the most practical and realistic approach. Consequently, as observed by Molise and Dube (2020) and Prynne (2021), new pedagogical practices that are inclined towards online learning have therefore been necessitated by the pandemic. Accordingly, Bir (2019) and Prynne (2021) contend that digitally mediated learning has been accelerated to compensate for the traditional mode of delivery which has become redundant. Among others, Dube (2020) and Sintema (2020) concur that online streaming and videos have been developed to provide for the loss of contact sessions. Thus, this paradigm shift in pedagogical practices exposed students to new ways of learning. Furthermore, some studies have found that university students' 
attitude towards e-learning influences their behavioural intention to use e-learning during the pandemic (Al-Okaily et al., 2020, Mailizar et al., 2021). Alshurafat et al. (2021) argue that although digitally mediated learning is a crucial solution for all universities, students have not been sufficiently trained to use e-learning systems.

However, research evidence on the ability of digitally mediated learning to provide students with effective and meaningful learning experiences is very limited. This arises from the fact that very little has been done to investigate the phenomenological experiences of students as they access the curriculum through technological and digital platforms. Nevertheless, Dube (2020), Coughlan (2021) and Sintema (2020) concur that the forced implementation of digitally mediated learning took the world by storm as it came with several challenges. To this effect, Krishnakumar and Rana (2020), Molise and Dube (2020), Prynne (2021), and Wells (2020) argue that this was exacerbated by the fact that not all institutions of higher learning were either ready for digitally mediated learning or had the necessary adequate infrastructure.

In addition, Basilaia and Kvavadze (2020), Coughlan (2021), and Krishnakumar and Rana (2020) observed that the academic staff who were supposed to be at the forefront of this digitally mediated learning did not have adequate competencies to switch readily to technological based pedagogies. To this end, access to technologically advanced resources by both lecturers and students has been deemed as an important determinant of the students' learning experiences with digitally mediated learning (Cramp \& Lamond, 2016; Wells, 2020). Contrary to this sentiment, Basilaia and Kvavadze (2020) found lecturers' lack of access to technological and digital resources as one of the factors which exposed students to less enabling and supportive learning experiences in a virtual learning environment. The above context is vital to the positioning of this study because it gives expression to the need to investigate the phenomenological learning experiences of accounting student teachers with digitally mediated learning.

Informed by the topic under investigation, the aim of this study was to investigate the learning experiences of fourth-year accounting student teachers with digitally mediated learning. In alignment with the aim of the study, the following research questions were posed in this study:

I. What are the experiences of fourth-year accounting student teachers with digitally mediated learning?

II. How do fourth-year accounting student teachers perceive their experiences with digitally mediated learning?

\section{Literature Review}

Students tend to experience effective and meaningful learning experiences in a student-centred learning environment in which active participation and open dialogue prevail (Mapuya, 2020). This is highly achievable in a learning environment which provides for a face-to-face mode of delivery (Cramp \& Lamond, 2016). In this regard, Cramp and Lamond (2016) subscribe to the earlier views of Vygotsky (1978), namely that the learning environment is a shared problem space in which students are invited to engage actively in knowledge construction through negotiation. By the same token, Macleod et al. (2016) advocate for a social constructivist approach to digitally mediated learning, which they believe is usually associated with a technologically supported learning environment. Central to this approach is its acknowledgement of the existing knowledge which students bring to the learning environment and how they actively build on this knowledge to construct new knowledge, meaning and understanding (Macleod et al, 2016). However, Cramp and Lamond (2016) and Prynne (2021) found active engagement and meaningful dialogue between the lecturer and students to be largely diminished in a digitally mediated learning environment.

In the current pedagogical dispensation of the COVID-19 era, Cramp and Lamond (2016) caution that lecturers have an obligation to design and shape the digital and technology-based virtual learning environment into a democratic and equitable learning space. This is necessary to provide students with Vygotsky's (1978) narrative of effective meaningful learning experiences. Contrary to this, Coughlan (2021) and Wells (2020) reported serious inequalities in access to learning opportunities in the digitally mediated learning environment. In support of this observation, an investigation by Cramp and Lamond (2016) found that while $70 \%$ of the participants engaged in digitally mediated learning, effective and meaningful learning was experienced by only $40 \%$ of the entire study sample. This is consistent with the findings of Basilaia and Kvavadze (2020), Dude (2020) and Prynne (2021) who found that most students, especially those from rural areas, do not have access to adequate connectivity or effective devices for digitally mediated learning. Similarly, a recent survey by Prynne (2021) found access to digitally mediated learning to be a problem among students who had limited access to resources, thereby compromising their learning.

Gaur et al. (2020) maintain that digitally mediated learning has provided lecturers with opportunities to include e-learning in the curriculum, and training in innovative technologies. Nevertheless, a survey conducted by Prynne (2021) revealed that $36 \%$ of the lecturers who participated in the survey had no experience of digitally mediated learning before the pandemic. From a South African perspective, Wells (2020) has observed a serious deterioration in 
access to equal and quality education since the advent of the COVID-19 pandemic. In another survey by Coughlan (2021), this observation is attributed to forced digitally mediated learning. Notwithstanding this reality, equal access to education and learning opportunities for every citizen remains a fundamental and non-negotiable human rights issue which is enshrined in the educational provisions, policies, frameworks and constitutions of many countries globally (Prynne, 2021). In South Africa, the Constitution of the Republic of South Africa (1994) and the Curriculum and Assessment Policy Statements (CAPS) (2011) provide unequivocally for this right.

According to Coughlan (2021), a survey conducted by the Independent Institute of Education, South Africa found lack of peer contact and motivation as key issues facing students with digitally mediated learning experiences. The psychological impact of digitally mediated learning was found to be very severe. Among others, the most distinguishable challenges of digitally mediated learning identified by the study and similar studies include lack of contact with peers, isolation, lack of motivation and a sense of anxiety and hopelessness (DeMara et al., 2019; Cramp \& Lamond, 2016; Dube, 2020; Vladova et al., 2021). The most recent findings by Prynne (2021) provide compelling evidence to argue that globally, students had more negative than positive learning experiences with digitally mediated learning.

Against this exposition, it therefore becomes necessary to explore the digitally mediated learning experiences of fourth-year accounting student teachers as a target population which has experienced the phenomenon under investigation. Subsequently, it becomes important to ensure that no student is left behind with digitally mediated learning. Of importance to this study is its call for a collaborative and mutually negotiated digitally mediated learning platform which conforms to conceptualizations of mediated, student-centred and supportive learning environments (Mapuya, 2020; Vygotsky, 1978).

\subsection{Digitally Mediated Learning Defined and Contextualized}

In the views of DeMara et al. (2019) and Prynne (2021), digitally mediated learning assumes that the lecturer supports the learning experiences of students using a shared virtual learning environment as opposed to teaching them directly. Cramp and Lamond (2016) add that instead of directg teaching and learning in the traditional way, the lecturer provides a supporting role for students to learn through a shared virtual learning environment. Amry (2014) further points out that digitally mediated learning uses emerging and new sophisticated pedagogical practices as well as the possibility of technologically supported learning and data analytics to support and enhance the attainment of learning objectives. Significant to the understanding of digitally mediated learning are the views of Amry (2014) who argues that it occurs beyond the physical learning environment, thereby enabling students to engage in learning regardless of time and distance constraints (Molise \&Dube, 2020). Subscribing to the above scholarly views, Mwakyusa (2016) and Cramp and Lamond (2016) are unanimous that digitally mediated learning happens when student learning is facilitated through information and communication technology-based platforms such as the Internet, computers and software.

After a comprehensive examination of relevant literature perspectives on the definition of digitally mediated learning, this study has concluded that online learning is a simplified version of digitally mediated learning. It therefore follows that within the scope of this study, online learning can be used interchangeably with digitally mediated learning, even though the latter is more complex and complicated.

\section{Research Methodology}

The study followed a qualitative approach embedded in a phenomenological research design, with focus group interviews being the data collection instrument. Babbie (2013) maintains that phenomenology strives to understand and clarify the people's perceptions and experiences, with reference to the meaning they ascribe to events, concepts and issues. In the same vein, Johnson and Christensen (2014) argue that the main purpose of phenomenology is to gain access into the world of study participants and to understand their perspectives. Gray (2014) contends that a phenomenological approach acknowledges that while the students are sitting in the same classroom, with the same lecturer, how they perceive the reality of their learning experience is very different. Each student brings a history of personal digitally mediated learning experiences, expectations, attitudes, behaviour and emotions, all of which influence how they view and perceive their learning experience in the South African context. There are numerous socio-economic challenges such as lack of a reliable supply of electricity which might affect effective implementation of digital learning in the country.

The population of the study comprised all the twenty-one fourth-year accounting student teachers at a comprehensive university in South Africa. These students were then divided into three focus group interviews which consisted of seven students each. The focus group interviews were numbered as focus group interview 1,2 and 3 while letters of the alphabet from $A$ to $G$ were used to represent each participant in the focus group interview. Owing to a relatively small 
target population, convenience sampling was used to select all the fourth-year accounting student teachers to participate in the study. Accordingly, the population of this study was also its sample. Data from the focus group interviews was recorded with the consent of the participants and later analyzed using content analysis. The findings were returned to interviewees to check for accuracy and resonance with their digitally mediated learning experiences.

\section{Presentation and Discussion of Findings}

The findings are presented in terms of the main themes that emerged from the focus group interviews and the subsequent key issues, followed by their respective discussions. The discussion of findings is presented in light of the two research questions that were posed and investigated in this study.

\subsection{Presentation of Main Themes and Key Issues Emerging from Themes}

Table 1. Themes and key issues emerging from focus group interviews

\begin{tabular}{|c|c|}
\hline Main themes & Key issues emerging from main theme (Sub-themes) \\
\hline $\begin{array}{l}\text { Flexible and convenient } \\
\text { learning experiences }\end{array}$ & $\begin{array}{ll}\text { - } & \text { Learning beyond the physical learning environment } \\
\text { - } & \text { Learning in the comfort of their private space } \\
\text { - } & \text { Learning at convenient times }\end{array}$ \\
\hline $\begin{array}{l}\text { Emotional } \\
\text { psychological } \\
\text { experiences }\end{array}$ & $\begin{array}{l}\text { - } \text { Marginalized and excluded } \\
\text { - Anxiety and hopelessness, uncertainty about the future } \\
\text { - } \quad \text { Depression and frustration, isolation and loneliness } \\
\text { - } \quad \text { Lack of social interaction and contact with peers } \\
\text { - } \quad \text { Demotivation }\end{array}$ \\
\hline $\begin{array}{l}\text { Technical } \\
\text { technological } \\
\text { experiences }\end{array}$ & $\begin{array}{l}\text { - } \\
\text { - } \\
\text { E-learning platforms used not user friendly }\end{array}$ \\
\hline $\begin{array}{l}\text { Socio-economic/ } \\
\text { financial challenges }\end{array}$ & $\begin{array}{l}\text { - } \quad \text { Expensive data, load shedding } \\
\text { - Lack of resources and infrastructure which support } \\
\text { digitally mediated learning } \\
\text { - } \quad \text { Effective and new devices expensive } \\
\text { - Students from poor and rural backgrounds struggled } \\
\text { more than their counterparts from rich and urban } \\
\text { backgrounds }\end{array}$ \\
\hline
\end{tabular}

4.2 Discussion of Findings in Light of the Research Questions

As indicated above, the findings of the study will be discussed within the confines of the research questions that were investigated. This discussion will culminate in conclusions and recommendations.

The following findings emerged with regard to the first research question which was investigated in this study and posed as:

- What are the experiences of fourth-year accounting student teachers with digitally mediated learning?

Responding to the above research question, the study established some convincing empirical evidence to confidently claim that the fourth-year accounting student teachers have both positive and negative experiences with digitally mediated learning. Regardless of either being negative or positive, these experiences were flexible and convenient learning, as well as emotional and psychological, technical and technological and lastly, socio-economic or financial experiences in nature. The students are unanimous about the positive experiences associated with digitally mediated learning, of which flexible and convenient learning experiences emerged as the main theme. The students unanimously agreed that digitally mediated learning presented them with learning beyond the physical learning environment, usually at convenient times and in their private spaces. To validate these findings, reference can be made to the sentiments of participant $2 \mathrm{~F}$ in Focus Group Interview 2 who had the following to say: 
Personally, I fell in love with the idea of not having to follow a strict timetable, because I could always choose to engage in learning at the best possible time for me when I could concentrate and be productive. I did not feel pressurized at all. This was so wonderful.

While all the other participants in Focus Group Interview 2 subscribed to these views, participant $3 \mathrm{C}$ in Focus Group Interview 3 went further to comment that:

Apart from convenient learning, I found it very beneficial that I could now learn outside the four walls of the classroom, I could learn even while laying on my bed or sitting in the garden. To me, this was the best experience of digitally mediated learning, guys, it was really nice not having to rush to the lecturer venue and instead, engage in learning wherever I was. It has been very comforting and encouraging. Sir, it was no longer necessary for me to be always worried about being late for class. I could attend anytime, anywhere.

Alluding to the phenomenological verdicts emerging from Focus Group Interviews 2 and 3 above, participant 1B made the following comment:

Looking back, the only good thing about this digitally mediated learning was that we were no longer compelled to be at a specific venue at given time to attend lecturers. This could happen everywhere, anytime.

However, while students are fully cognizant of the benefits of digitally mediated learning, they are not aware that these benefits can only be enjoyed when the lessons are recorded and shared with them. These benefits cease when the lesson presentation is conducted on a live online platform, and is not recorded or shared with students. They will still have to $\log$ in at the specified time, regardless of where they are. Similarly, Alshurafat et al. (2021) have found that social trust influences the perceived usefulness and perceived ease of use of digitally mediated learning by accounting education students during the COVID-19 pandemic.

The main theme emerging from the phenomenological voices of students regarding their negative experiences suggests that the emotional and psychological effects of digitally mediated learning are disconcerting. Among other emotional and psychological experiences associated with digitally mediated learning, students agree that they experienced depression, anxiety, uncertainty, hopelessness, frustration, demotivation and isolation from their classmates.

To corroborate this prognosis, participant 2D in Focus Group Interview 2 revealed the following:

Coming from a schooling background of being in a live and physical classroom set up, I felt alone and lost when I had to all this online learning alone, wondering what was happening to my friends and if I was learning the right things. At one point I thought this was the end of it all.

In Focus Group Interview 3, participant 3F had this to say:

Colleagues, I never saw this coming and to confess, I could not just see myself succeeding with this type of learning. There are times when giving up seemed to be the best option I had. Had it not been because of the constant emails and texts we received from you, Sir, I doubt I would still be around, especially during the early days of digitally mediated learning.

The magnitude of negative experiences was summed up by participant 1E in Focus Group Interview 1 as follows:

Having been exposed to live one-on-one teaching experiences throughout my academic career, I never imagined that a day would come when I would have to engage in learning in my own small little corner, feeling abandoned, without any hope of being reunited with my lecturers and classmates. Initially, it was all dark and gloom, I could neither think nor concentrate. I was very reluctant to let go of the old way of learning.

Participant 1A in Focus Group Interview 1 added the following:

And then, there was this issue of data and Internet connection, which proved to be the core prerequisites of this type of learning. Sometimes network was so cruel that it would kick me out from the lesson for the whole day, and when it eventually decided to behave, data will be gone. This was just a lot of stress. To be honest, I feel very lucky to have made it this far.

These negative emotional and psychological experiences of students emanated from a host of factors. However, the most distinctive ones in this regard included challenges in evaluating the learning progress of students in real time, providing immediate feedback and promoting meaningful interactions between the lecturer and the students and among the students themselves.

Evidence in support of the above finding is found in the verbatim expressions of participant $2 \mathrm{~A}$ in Focus Group Interview 2 who lamented the following: 
I have always been inspired and driven by immediate feedback to my responses when I answer questions in class, because in getting this feedback, I also got to be corrected. But with this thing of digitally mediated learning, I had to wait for days and sometimes weeks before getting feedback and corrections.

Citing the lack of immediate feedback as a major blow to their learning, participant $3 \mathrm{~A}$ in Focus Group Interview 3 responded as follows:

By the time this feedback comes, we are already dealing with a different topic, and I would never bother to go back and check where exactly I went wrong. So, it was basically responding and submitting without any meaningful feedback on time which I could relate my responses to immediately.

The absence of meaningful and live interactions between the lecturer and the students was mentioned by participant $1 \mathrm{C}$ who complained as follows:

I personally missed the vibrant engagements and interactions I had in class with the lecturer and my classmates before this covid-19. It was very unusual to go through a lesson without sharing and interrogating each other's views. I sometimes felt the need to confirm and verify my views and responses, but there I was, all on my own, alone.

This supports the findings of DeMara et al. (2019) and Mapuya (2020) whose separate studies also came to a similar conclusion regarding digitally mediated learning experiences.

The above sentiments of students demonstrate a collective expectation that institutions of higher learning and the government should take ownership of digitally mediated teaching and learning in terms of capacity building, empowerment, and the supply of relevant resources. Thus, in their capacity as the custodians and gatekeepers of teaching and learning, institutions of higher learning and their respective ambits of the government have a duty to make digitally mediated teaching and learning effective and successful in the new educational dispensation of the COVID-19 pandemic era.

The response to the second research question investigated in this study has been found to be embedded in the study findings above regarding the first research question. Thus, the second research question was presented as:

\section{- How do fourth-year accounting student teachers perceive their experiences with digitally mediated learning?}

Reliably informed by the findings for the first research question, the study concluded that the fourth-year accounting student teachers perceived their experiences with digitally mediated learning to be both positive and negative. The positive perceptions of their experiences with digitally mediated learning emanated from the fact that they experienced flexible and convenient learning experiences. To be more specific, this implies that they could not only learn beyond the physical learning environment in the comfort of their private spaces, but they could also engage in learning at times that were convenient to them.

Correspondingly, the fourth-year accounting student teachers perceived their digitally mediated learning experiences to be fundamentally negative. These negative perceptions were based on the students' emotional and psychological experiences, technical and technological experiences and socio-economic or financial experiences. As indicated in the findings to the first research question above, to validate these negative perceptions of their experiences with digitally mediated learning, the fourth-year accounting student teachers recalled that they felt marginalised and excluded, and were anxious, hopeless, depressed, isolated, and lonely. Such emotional and psychological experiences were largely an outcome of the absence of social interaction and contact with their peers and lecturer, which also demotivated them.

Technical and technological experiences also led the fourth-year accounting student teachers to perceive their experiences with digitally mediated learning as negative because they experienced connectivity problems because of ineffective devices. Lastly, the socio-economic and financial challenges experienced by the fourth-year accounting student teachers made it inevitable for them to perceive their digitally mediated learning experiences as negative. To illuminate this prognosis, the students, as indicated above in the responses to the first research question, cited expensive data, load shedding and lack of access to effective devices to support digitally mediated learning as the serious challenges which they experienced with digitally mediated learning.

\section{The Limitations of the Study, Implications, and Suggestions for Future Research}

The researchers wish to acknowledge the absence of comparative data from either a different population or university as a potential limitation of this study. Comparative data would have been very useful in solidifying and vindicating the findings of this study and in enriching the contribution this study has made towards understanding the phenomenological experiences of students with digitally mediated learning. In light of the above-mentioned limitation, it is therefore suggested that studies of a similar nature and purpose be conducted with different groups of students 
from more than one university. Notwithstanding this limitation, the findings of this study have some serious implications on digitally mediated learning. A major implication is that the needs and contextual circumstances of students need to be put into consideration when developing learning material on digital learning platforms. Most importantly, the needs and contextual circumstances of students should always find adequate expression, not only in the manner in which learning materials and lessons are presented, but also on how these digital learning platforms reflect the profiles of those students who they intend to serve.

\section{Conclusion}

Despite the inherent challenges that have emerged in this study, the phenomenon of digitally mediated learning is now a reality facing both lecturers and students in accounting education. Noting that digitally mediated learning is no longer a choice, lecturers need to reflect and think coherently and consciously about the new roles that have emerged because of technologically based learning in higher education. Some of these roles are to develop material which students can meaningfully interact with and create and maintain a live, interactive virtual learning environment in which student learning is monitored and evaluated continuously. This process needs to be guided and informed by the phenomenological verdicts of students on their learning experiences in that virtual learning environment. The institutions of higher learning and the government should capacitate lecturers and students and provide them with the necessary resources to engage successfully and effectively in digitally mediated learning in pursuit of learning outcomes and educational goals. More than ever, these initiatives must be student driven and demonstrate an accentuated approach towards the creation of a student-centred virtual learning environment which thrives on digital technology.

\section{References}

Al-Okaily, M., Alqudah, H., Matar, A., Lutfi, A., \& Taamneh, A. (2020). Dataset on the acceptance of e-learning system among universities students' under the COVID-19 pandemic conditions. Data Brief, 32, https://doi.org/10.1016/j.dib.2020.106176

Alshurafat, H., Al Shbail, M. O., Masadeh, W. M., Dahmash, F., \& Al-Msiedeen, J. M. (2021). Actors affecting online accounting education during the COVID-19 pandemic: An integrated perspective of social capital theory, the theory of reasoned action and the technology acceptance model. Education and Information Technologies, 1-19. https://doi.org/10.1007/s10639-021-10550-y

Amry, B. A. (2014). The impact of WhatsApp mobile social learning on the achievement and achievement of female students compared with face to face learning in the classroom. European Scientific Journal, 10(22), 116-136. https://doi.org/10.19044/esj.2014.v10n22p\%25p

Babbie, E. (2013). The Practice of Social Research. Cengage Learning.

Bir, D. D. (2019). Comparison of academic performance of students in online vs traditional engineering course. European Journal of Open, Distance and e-Learning, 22(1), 1-13. https://doi.org/10.2478/eurodl-2019-0001

Coughlan, F. (2021). Higher education COVID response: Connection key to positive outcomes. Independent Institute of Education, South Africa. https://www.advtech.co.za/higher-education-COVID-response-connection-key-to-positive-outcomes-survey

Cramp, A., \& Lamond, C. (2016) Engagement and kindness in digitally mediated learning with teachers. Teaching in Higher Education, 21(1), 1-12. https://doi.org/10.1080/13562517.2015.1101681

DeMara, R. F., Campbell, L. O., Hartshorne, R., Spiegel, S., \& Katz, J. G. (2019, October 3-4). Community report on digitally-mediated team learning: Advancing collaborative problem-solving within the STEM classroom. [Paper presentation]. NSF Conference on Cyberlearning, Alexandria, VA, USA. https://cal.ucf.edu/publications/

Dube, B. (2020). Rural online learning in the context of COVID-19 in South Africa: Evoking an inclusive education approach. Multidisciplinary Journal of Educational Research, 10(2), 135-157. https://doi.org/10.17583/remie.2020.5607

Gaur, U., Majumder, M. A. A., Sa, B., Sarkar, S., Williams, A., \& Singh, K. (2020). Challenges and opportunities of preclinical medical education: COVID-19 crisis and beyond. SN Compr Clin Med, 1-6. https://doi.org/10.1007/s42399-020-00528-1

Gray, D. E. (2014). Doing Research in the Real World. SAGE.

Johnson, B., \& Christensen, L. (2014). Educational Research. Quantitative, Qualitative and Mixed Approaches. SAGE. 
Krishnakumar, B., \& Rana, S. (2020). COVID-19 in INDIA: Strategies to combat from combination threat of life and livelihood. Journal of Microbiology, Immunology and Infection, 53(3), 389-391. https://doi.org/10.1016/j.jmii.2020.03.024

Macleod, H., Sinclair, C., Haywood, J., \& Woodgate. A. (2016). Massive open online courses: Designing for the unknown learner. Teaching in Higher Education, 21(1), 13-24. https://doi.org/10.1080/13562517.2015.1101680

Mailizar, M., Burg, D., \& Maulina, S. (2021). Examining university students' behavioural intention to use e-learning during the COVID-19 pandemic: An extended TAM model. Education and Information Technologies. https://doi.org/10.1007/s10639-021-10557-5

Mapuya, M. (2020). First-year accounting student teachers' perceptions of their classroom learning environment. International Journal of Learning, Teaching and Educational Research, 19(12), 30-42. https://doi.org/10.26803/ijlter.19.12.2

Molise, H., \& Dube, B. (2020). Emergency online teaching in economic and management sciences necessitated by the COVID-19 pandemic: The need for healthy relations in a rural schooling context. International Journal of Teaching, Learning and Educational Research, 19(6), 387-400. https://doi.org/10.26803/ijlter.19.6.23

Musarurwa, C. (2011). Teaching with and learning through ICTs in Zimbabwe's teacher education colleges. US-China Education Review, A 12(2011), 1-9. https://www.researchgate.net/publication /283047665_Teaching_With_and_Learning_Through_ICTs_in_Zimbabwe's_Teacher_Education_College

Prynne, M. (2021). The campus: Digital teaching survey special report. https://campus-cms.prd.timeshighereducation.com/sites/default/files/2021-02/THEDigitalTeachingSurveyspecia 1 report.pdf

Sintema, E. J. (2020). Effect of COVID-19 on the performance of grade 12 students: Implications for STEM education. Eurasia Journal of Mathematics, Science and Technology Education, 16(7), 1-6. https://doi.org/10.29333/ejmste/7893

Vladova, G., Ullrich, A., Bender, B., \& Gronau, N. (2021). Students' acceptance of technology-mediated teaching how it was influenced during the COVID-19 pandemic in 2020: A study from Germany. Frontiers in Psychology, 12, 636086. https://doi.org 10.3389/fpsyg.2021.636086

Vygotsky, L. S. (1978). Mind in society: Development of higher psychological processes. Harvard University Press.

Wells, J. (2020). While the world paused on COVID-19, human rights abuses accelerated. https://www.dailymaverick.co.za/article/2020-12-08-while-the-world-paused-on-COVID-19-human-rights-abus es-accelerated/

\section{Copyrights}

Copyright for this article is retained by the author(s), with first publication rights granted to the journal.

This is an open-access article distributed under the terms and conditions of the Creative Commons Attribution license (http://creativecommons.org/licenses/by/4.0/). 